ISSN: 1641-4713; e-ISSN: 2081-1160

DOI: https://doi.org/10.36551/2081-1160.2021.27.75-94

\title{
O Trabalho e a Cidade: Uma análise do serviço doméstico e a circulação de criadas estrangeiras na cidade do Rio de Janeiro (1880-1930)
}

\author{
Work and the City: An analysis of domestic service and the circulation \\ of foreign maids in the city of Rio de Janeiro (1880-1930)
}

\author{
Natália Batista Peçanha \\ Universidade Federal do Piauí, Brasil \\ ORCID ID: https://orcid.org/0000-0003-2013-106X \\ E-mail: nataliahist@hotmail.com
}

Recepción: 30.11 .2020

Aprobación: 20.06.2021

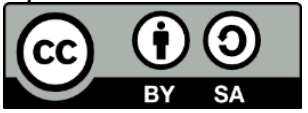

Resumo: Desde a escravidão, o serviço doméstico era uma das atividades laborais que mais empregava mulheres, sobretudo as de cor, que até hoje é a parcela da população que mais ocupa tal atividade, no Brasil. Entretanto, a pesquisa apresentada tem como objetivo analisar a participação das criadas europeias no serviço doméstico carioca, destacando as formas pelas quais se inseriam na dita atividade; quais as nacionalidades eram mais demandadas e ofertadas; bem como investigar a circulação dessas personagens na cidade do Rio de Janeiro. Para isso, lançaremos mão de documentos como anúncios de jornais presentes em periódicos cariocas, como o Jornal do Commercio, mapas confeccionados a partir de dados coligidos em tais anúncios, que serão analisados a partir de uma perspectiva da História Global do Trabalho. Assim, a partir dos endereços disponibilizados nos anúncios, foi realizado um mapeamento de tais localizações das demandas por criadas/os estrangeiras/os e de sua oferta, verificando, portanto, a espacialização dessas personagens na Capital Federal e as condições de trabalho provenientes.

Palavras-chave: serviço doméstico, imigração europeia, mundos do trabalho, anúncios, Rio de Janeiro.

Abstract: Since slavery, domestic service was one of the work activities that most employed women, especially those of color, which to this day is the portion of the population that most occupies such activity in Brazil. However, the research presented aims to analyze the participation of 
European maids in the carioca domestic service, highlighting the ways in which they inserted themselves in said activity; which nationalities were most in demand and offered; as well as investigating the circulation of these characters in the city of Rio de Janeiro. For this, we will make use of documents such as newspaper advertisements present in Rio de Janeiro periodicals, such as Jornal do Commercio, maps made from data collected in such advertisements, which will be analyzed from a perspective of Global Labor History. Thus, from the addresses available in the advertisements, a mapping of such locations of demands by foreign servants and their offer was carried out, thus verifying the spatialization of these characters in the Federal Capital and the resulting working conditions.

Keywords: domestic service, European immigration, worlds of work, newspaper ads, Rio de Janeiro.

INTRODUÇÃO

O serviço doméstico é uma atividade que arregimenta uma parcela significativa das mulheres economicamente ativas no Brasil ${ }^{1}$ que experimentam desigualdades de gênero, classe e raça em sua labuta. Essas desigualdades vivenciadas por empregadas domésticas assumem cada vez mais um papel de destaque em estudos das diversas disciplinas das Ciências Humanas que apresentam outras/os agentes sociais que também vivenciam preconceitos e estigmas em sua condição de outsider - os/as imigrantes (Andall, 2017; Momsen, 1999). Trabalhos como o de Cole e Booth (2007) buscam trazer à tona a relação entre imigração e serviço doméstico, em cenários de busca por melhores condições de vida das populações que experimentam condições político-econômicas desfavoráveis em sua terra natal. Ao analisar como a Sicília se converteu em destino privilegiado para "centenas de Tunisianos, Bangladeshis, Filipinos, Nigerianos, Sri Lankas, e outros", por exemplo, é identificado que os referidos imigrantes, uma vez estabelecidos, se lançavam em três tipos de "dirty work": serviço doméstico, prostituição e agricultura - "caracterizados pela disparidade de pagamento, segurança e prestígio" (Cole \& Booth, 2007).

No cenário da circulação de pessoas, é notório perceber que mulheres cruzaram países e buscaram melhores condições de vida, seja com suas famílias e companheiros, seja individualmente, por toda a história. Entretanto, na historiografia brasileira, só muito recentemente as experiências migratórias femininas estão sendo consideradas dados de pesquisa. Conforme, de Medeiros e de Matos, a "invisibilidade do feminino nos estudos dos processos de e/imigração tendeu

\footnotetext{
${ }^{1}$ De acordo com o PNAD Contínua organizada pelo IBGE, “a categoria dos trabalhadores domésticos (6,4 milhões de pessoas) aumentou 3,1\%no confronto com trimestre de julho a setembro de 2017. Frente ao trimestre de outubro a dezembro de 2016, houve alta de 4,3\% (mais 262 mil pessoas)" (IBGE, 2017). Este estudo verificou que a média da taxa de desocupação brasileira em 2017 foi e 12,7\%.
} 
a ser justificada pela menor porcentagem de mulheres nas partidas oficialmente computadas". (de Medeiros \& de Matos, 2017).

É a partir da análise da presença da imigração europeia no serviço doméstico que buscamos analisar as formas de inserção destes/as trabalhadores/as ao mundo do trabalho ${ }^{2}$ carioca e sua circulação na cidade, no período de 1880 a 1930. Tal recorte temporal, justifica-se por englobar diversas mudanças sociais, como o processo de emancipação e o fortalecimento do pensamento liberal. Além disso, o recorte engloba o que se convencionou chamar de "grande imigração", período pelo qual milhões de imigrantes europeus/ias aportaram em territórios do continente americano, como Argentina, EUA, Canadá e Brasil. No caso brasileiro, alguns autores, como Herbert S. Klein, por exemplo, enquadram a "grande imigração", ou "imigração em massa", ao período de 1880-1915, uma vez verificada uma queda na taxa de imigração com o início da Primeira Guerra Mundial (Klein, 2000). Entretanto, autores como Érica Sarmiento da Silva e Jair de Souza Ramos, estendem este período até 1930 pelo fato da imigração ainda se mostrar relevante (de Silva, 2009; Ramos, 1996). Seguindo estes últimos autores, a justificativa para a escolha do período de 1880-1930 dar-se-á pelo fato de ser um período importante para o processo de imigração, além da década de 1880, representar um momento decisivo tanto para a consolidação do fim da escravidão como para a imigração que já alcançava taxas significativas. De acordo com da Costa Leite (2000), a década de 1880 foi um ponto alto na imigração de portugueses, italianos e alemães para o Brasil.

Assim, definidos os objetivos e recortes, passemos às análises sobre a presença de mulheres imigrantes no serviço doméstico carioca, a partir de uma investigação feita nos documentos supracitados, mas, sobretudo, em anúncios de ofertas e demandas de criadas, presentes no periódico Jornal do Commercio.

\footnotetext{
2 Por mundos do trabalho, partimos de uma concepção muito afinada à História Social do Trabalho, influenciado pelos estudos thompsonianos, e, também, da História Global do Trabalho, que busca em primeiro lugar, superar a dicotomia entre trabalho livre e coercitivo ou escravo, trabalho urbano e rural, formal e informal. Além disso, promove uma análise que abarca questões que vão para além das análises sobre os meios de produção, por exemplo, ao considerar as experiências dos trabalhadores envolvendo relações de trabalho às de gênero, classe raça e etnia; cotidiano e culturas de classe, dentre outros aspectos, que nos permitem uma análise mais ampla das relações laborais. Ver Fortes et al., 2013; van der Linden, 2013.
} 


\section{A IMIGRAÇÃO EUROPEIA NO SERVIÇO DOMÉSTICO CARIOCA A TRAVÉS DE ANÚNCIOS DE OFERTA E DEMANDA}

Ao final do século XIX, o Brasil experimentou mudanças sociais significativas. Se a abolição foi um dos processos mais impactantes em relação a vida política, social e em relação aos mundos do trabalho, a "grande imigração" também teve uma relevância a ser destacada. Para ter um melhor entendimento desse contexto, as cifras sobre as grandes migrações do final do século XIX e início do século XX, nos mostram um número crescente de homens e mulheres partindo de países europeus rumo às Américas, favorecidos por avanços tecnológicos que permitiram a comunicação mais ágil e mais barata entre a Europa e a América. ${ }^{3}$ Assim, cerca de 31 milhões de pessoas cruzaram o Atlântico rumo ao Novo. Para o Brasil, entre 1890 e 1914, cerca de 2,5 milhões de europeus migraram, sendo 987 mil subsidiados pelo Estado sob a forma de custeio das viagens. ${ }^{4}$ No caso do Rio de Janeiro, no ano de 1872, havia 190.689 brasileiros e 84.283 estrangeiros, sendo 158.766 homens e 116.206 mulheres (69\% de nacionais e $31 \%$ de estrangeiros). Em 1890, o percentual de estrangeiros em relação aos nacionais permanece parecido: 367.449 nacionais para 155.202 estrangeiros $(70 \%$ de nacionais e $30 \%$ de estrangeiros) (Ribeiro, 1987).

Muitos vinham de regiões como o Leste e Sul europeu, até então em cifras inferiores, frente à imigração do Norte que prevaleceu até a década de 1880 . Esses imigrantes do Leste e Sul da Europa, geralmente eram homens, jovens pouco qualificados, que pretendiam "fazer a América" e regressar à sua terra natal. O retorno aconteceu para cerca de $65 \%$ dos imigrantes desembarcados, entre 1899 e 1912, no Brasil. Só não sabemos se esse retorno estava associado ao sucesso em terras estrangeiras ou as desilusões frente às condições de vida experimentadas (Galeano, 2012, p. 73). O mais provável é que o retorno por sucesso tenha sido inferior aos motivados por desilusões e/ou extradições.

Mulheres e homens que permaneciam e tentavam manter a vida, a adaptação ao novo país, geralmente, se dava pela inserção no trabalho. No caso das mulheres, o caminho mais fácil era a sua contratação para o serviço doméstico,

\footnotetext{
${ }^{3}$ Como avanços tecnológicos que favoreceram a comunicação entre o Velho Mundo e o Novo, podemos destacar: a substituição da vela pela energia a vapor nos navios de passageiros, a instalação do primeiro cabo telegráfico transatlântico, em 1866, e o término de um conjunto de ligações ferroviárias, por volta de 1870 (Fausto, 2000).

${ }^{4}$ Klein, ao analisar a migração internacional para as Américas, cita um número próximo ao já citado - entre 1881 e 1915, cerca de 31 milhões de imigrantes chegaram às Américas, sendo 2,9 milhões para o Brasil (Klein, 2000).
} 
seja através de um contato prévio estabelecido por um/a patrício/a que já residia aqui e intermediava alguma casa de família para a recém-chegada se instalar; seja pela intermediação de agências de locação que enchiam as páginas do Jornal do Commercio, com centenas de anúncios que colocavam à disposição das famílias, as mais variadas demandas de pessoas especializadas em algum serviço doméstico.

Nas tabelas a seguir, verificam-se as diversas nacionalidades de criadas ofertadas e demandadas nos anúncios do Jornal do Commercio. ${ }^{5}$

TABELA 1. QUANTIDADE DE REFERÊNCIAS ÀS NACIONALIDADES DAS CRIADAS OFERTADAS (ALUGA-SE), JORNAL DO COMMERCIO (1882-1932)

\begin{tabular}{|l|r|r|r|r|r|r|r|r|r|r|r|r|}
\hline & 1882 & 1887 & 1892 & 1897 & 1902 & 1907 & 1912 & 1917 & 1922 & 1928 & 1932 & Total \\
\hline Portuguesa & 7 & & 1 & 1 & 2 & 6 & 52 & 5 & & 2 & 1 & 77 \\
\hline Espanhola & 1 & & 1 & & & & 2 & & & & & 4 \\
\hline Francesa & 2 & & 1 & 1 & & 2 & & & & & & 6 \\
\hline Alemã & 2 & & 1 & 1 & & & 1 & & & & 1 & 6 \\
\hline Americana & & & & & & & & 1 & & & & 1 \\
\hline Europeia & & & & & 1 & & & & & & & 1 \\
\hline Estrangeira & & 2 & & 1 & 2 & 4 & 1 & 2 & 1 & & & 13 \\
\hline $\begin{array}{l}\text { Inglesa ou } \\
\text { Alemã }\end{array}$ & & 1 & & & & & & & & & & 1 \\
\hline $\begin{array}{l}\text { Chegada } \\
\text { da Europa }\end{array}$ & & & & & 1 & & 2 & & & & & 3 \\
\hline Nacional & 4 & & & 1 & & & 2 & & & & & 7 \\
\hline Não inf. & 107 & 9 & 41 & 43 & 23 & 24 & 48 & 15 & 2 & 12 & 5 & 329 \\
\hline
\end{tabular}

Fonte: Jornal do Commercio - primeira segunda-feira de novembro dos anos de 1882 a 1932, respeitando o intervalo de cinco anos.

\footnotetext{
${ }^{5}$ Para os dados coletados a partir do Jornal do Commercio, foram realizadas pesquisas prévias; foram selecionados anúncios publicados desde a criação do jornal, em 1827. Como a quantidade de anúncios em um único exemplar era extensa, ao contrário do que ocorria com $O$ Paiz e outras folhas, foram selecionados anúncios publicados em um dia fixo da semana do mês de novembro, entre os anos de 1827 e 1932, obedecendo a um intervalo de cinco anos entre uma segunda-feira e outra do referido mês. Como o recorte temporal da presente pesquisa se limita ao período de 1880 a 1930, a escala de análise foi reduzida e os dados coletados foram selecionados para serem inseridos no recorte proposto para, a partir dos anúncios, localizar as pessoas imigradas da Europa no serviço doméstico.
} 
TABELA 2. QUANTIDADE DE REFERÊNCIAS ÀS NACIONALIDADES DAS CRIADAS DEMANDADAS (PRECISA-SE), JORNAL DO COMMERCIO (1882-1932)

\begin{tabular}{|c|c|c|c|c|c|c|c|c|c|c|c|c|}
\hline & 1882 & 1887 & 1892 & 1897 & 1902 & 1907 & 1912 & 1917 & 1922 & 1928 & 1932 & Tota \\
\hline Portuguesa & 1 & & & 1 & 1 & 2 & 1 & & & 1 & 1 & 8 \\
\hline Espanhola & & & 1 & 1 & & & & & & & & 2 \\
\hline Francesa & & 1 & & & & & & 1 & & & & 2 \\
\hline Alemã & & & 1 & & & & 1 & & & & & 2 \\
\hline Inglesa & & & & & & & & & & 1 & & 1 \\
\hline Estrangeira & 1 & & 4 & 1 & 2 & & & 1 & & 1 & & 10 \\
\hline $\begin{array}{l}\text { Nacional } \\
\text { ou es- } \\
\text { trangeira }\end{array}$ & & & 1 & & & & & & & & & 1 \\
\hline $\begin{array}{l}\text { Francesa, } \\
\text { Suíça ou } \\
\text { Belga }\end{array}$ & & & & & & & & & 1 & & & 1 \\
\hline $\begin{array}{l}\text { Portuguesa } \\
\text { ou Alemã }\end{array}$ & 2 & & & & & & & & & & & 2 \\
\hline Oriental & & & & 1 & & & & & & & & 1 \\
\hline Nacional & & & & 1 & & 1 & 1 & & & & & 3 \\
\hline Não inf. & 60 & 68 & 108 & 61 & 42 & 79 & 38 & 13 & 8 & 6 & 43 & 526 \\
\hline
\end{tabular}

Fonte: Jornal do Commercio - primeira segunda-feira de novembro dos anos de 1882 a 1932, respeitando o intervalo de cinco anos.

A tabela nos revela um padrão bem conhecido da imigração europeia em solo carioca - a presença majoritária de portugueses. ${ }^{6}$ Tal dado, pode justificar o predomínio de anúncios de empregadas/os portuguesas/es em relação às outras nacionalidades. Estamos falando de um processo de imigração em que há um número significativamente maior de portugueses em relação às outras nacionalidades. Este fenômeno, além de gerar um número considerável de trabalhadores

\footnotetext{
${ }^{6}$ Em 1906, por exemplo, dos 811.443 habitantes, 133.393 eram portugueses, seguidos por 25.557 italianos, 20.699 espanhóis, 3.474 franceses, 2.575 alemães (Rio de Janeiro, Oficina de Estatística, 1907). Apesar dos italianos comporem uma parcela significativa da população estrangeira carioca, a maior parte dos/as italianos/as era ligada ao comércio ambulante. Outra profissão geralmente desempenhada pelos italianos era a de engraxate, além dos ofícios de amolador, sapateiro, varredor de ruas, pedreiro, garçom, operário têxtil, alfaiate, barbeiro, marceneiro, jardineiro. "Com o correr do tempo, foi-se formando uma classe restrita de profissionais (sobretudo jornalistas, artistas e maestros), outra mais ampla de comerciantes e alguns industriais, cujo número chegava a 56, em 1907, entre o Estado do Rio de Janeiro e o Distrito Federal, e a 89, em 1920, mas com uma média de 9,4 operários por fábrica" (Trento, 1989).
} 
economicamente ativos disponíveis ao mercado de trabalho, gerava também, um outro fenômeno que foi bem característico até os primeiros anos republicanos o antilusitanismo (Chalhoub, 2001; Ribeiro, 1987), que se faz presente também nos anúncios analisados que seguem:

Precisa-se de uma boa e carinhosa ama de leite, branca ou de cor, não sendo portuguesa; trata-se na rua do Souto n. 17. [grifo meu]. ("Precisa-se de uma boa e carinhosa ama de leite", 1920)

Criada estrangeira - precisa-se de uma (que não seja portuguesa); na Avenida Atlântica n. 250, Leme. [grifo meu]. ("Criada estrangeira - precisa-se de uma”, 1910)

Apesar de verificarmos as tensões e rixas que muitos nacionais possuíam em relação aos portugueses, é fato a integração desses imigrantes à população nativa. Os anúncios revelam que, apesar das desconfianças que portugueses geravam à parcela dos nacionais, é notório que a imagem da/o portuguesa/ês morigerada/o sobressaía quando se precisava de criadas/os estrangeiras/os.

Precisa-se de uma arrumadeira; na Avenida Gomes Freire n. 129, prefere-se portuguesa. ("Precisa-se de uma arrumadeira", 1910)

Precisa-se de uma criada para cozinhar e mais serviços de duas senhoras; na rua Visconde do Rio Branco n. [ileg.], sobrado. Prefere-se portuguesa. ("Precisa-se de uma criada para cozinhar e mais serviços", 1915)

Precisa-se de uma copeira e arrumadeira para casa de família, prefere-se portuguesa; trata-se na praia do Flamengo. ("Precisa-se de uma copeira e arrumadeira", 1915)

Além da construção da narrativa de que o imigrante europeu era a expressão do bom trabalhador, outro aspecto poderia se destacar em relação a preferência por uma criada imigrante: a elevação do status social. Analisando alguns costumes da sociedade carioca do século XIX, verifica-se a aversão, entre a população livre, sobretudo mais abastada, aos trabalhos manuais. ${ }^{7}$ Por isso, possuir uma quantidade significativa de escravos domésticos, representava não só a repulsa dos senhores a essas atividades, como também uma questão de status social. Quanto maior o número destes serviçais, mais se poderia ostentar a posição social de uma família (Soares, 2007). Entretanto, nas últimas décadas do século XIX, observa-se uma alteração nesse padrão. A criada europeia passa a ocupar o nível mais alto no status social da casa que cabia a uma trabalhadora. Luiz Edmundo, ao descrever os grandes palacetes de início do

\footnotetext{
${ }^{7}$ Sidney Chalhoub identifica que, após a abolição da escravidão, a aversão ao trabalho começa a ser repensada e reajustada no universo mental da classe dominante. A abolição colocava em questão a possibilidade do liberto não querer se sujeitar ao trabalho. Daí a necessidade do conceito de trabalho ter que "se despir de seu caráter aviltante e degradador característico de uma sociedade escravista, assumindo uma roupagem nova que lhe desse um valor positivo" (Chalhoub, 2001).
} 
século XX, destaca que as "famílias tomam governantas inglesas e alemãs para seus filhos. E não mandam, em geral, as filhas a internatos. Educam-nas em casa, para isso contratando os mais afamados professores" (Edmundo, 2003, p. 200).

Os grandes palacetes de Botafogo e Flamengo, por exemplo, certamente eram destinos de muitas dessas criadas europeias que se inseriam no serviço doméstico carioca. Entretanto, cabe verificar através dos anúncios, como se dava essa circulação geográfica na cidade. Será que essas criadas estrangeiras eram demandadas apenas por regiões marcadas pela presença de uma elite carioca? Ou será que pelo perfil dessa imigração, tais criadas poderiam ser demandas em regiões não tão elitistas assim? Os anúncios, portanto, poderão nos ajudar a responder tais questões.

Essas localizações geográficas verificadas a partir dos anúncios, implicitamente, permitem acompanhar o processo de reformas urbanas pela qual a Capital Federal passou entre 1868 (primeiras concessões para linhas de bondes) e 1905 (auge das reformas urbanas empreendidas pelo Governo Federal e pelo Prefeito Pereira Passos) (Benchimol, 1992, p. 97). Essas reformas propiciaram um deslocamento urbano de uma parcela da sociedade mais abastada para regiões mais afastadas da região central do Rio. ${ }^{8}$ Além disso, facilitou a circulação de trabalhadores/as que, a partir da segunda metade do século XIX, eram, em sua maioria numérica, cada vez mais de condição civil livre. ${ }^{9}$ Essa facilidade, se deu graças à evolução dos meios de transportes experimentada, a partir de 1868, quando há a inauguração dos carris urbanos da Botanical Garden Company, que ligava a Rua Gonçalves Dias ao Largo do Machado, contribuindo para a história da urbanização da Zona Sul Carioca (Benchimol, 1992, p. 97).

\footnotetext{
${ }^{8}$ No caso da Zona Sul, não podemos dizer que sua população foi composta apenas pelas classes dominantes. De acordo com Maurício de Abreu, essa zona administrativa possuía, em sua composição social, uma população não aristocrática composta, sobretudo, por imigrantes portugueses engajados no comércio, em terrenos menos valorizados, como os arredores do cemitério de São João Batista. Além disso, com a proliferação de habitações coletivas, como os cortiços, regiões como Botafogo também abrigava uma importante camada popular (Benchimol, 1992).

${ }^{9} \mathrm{Em} 1870,57 \%$ das criadas no Rio de Janeiro eram livres, essa tendência foi só aumentando, uma vez que através do censo de 1872 , observamos a presença de $63 \%$ de livres desempenhado a atividade de criada (Graham, 1992).
} 
Mapa 1. Rua Gonçalves Dias ao Largo do Machado

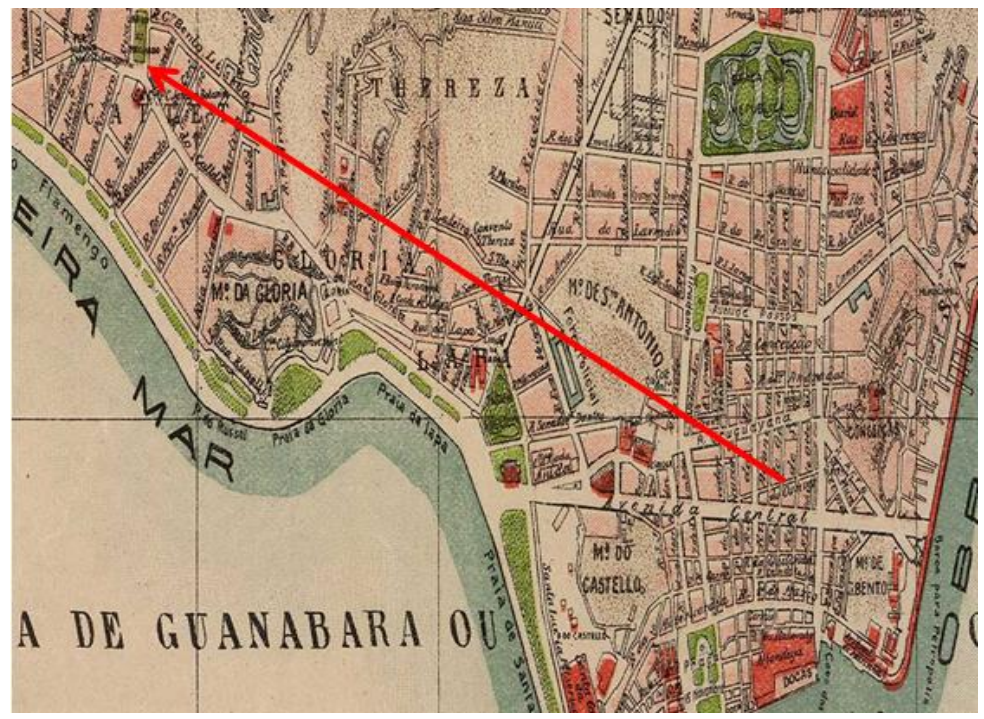

Fonte: Distrito Federal, 1907.

Conforme se proliferavam os bairros residenciais de caráter mais "aristocrático", um mercado de trabalho local começou a se desenvolver em torno de atividades como o comércio (tanto formal quanto informal); a exploração de pedreiras e a prestação de serviços domésticos, como o caso da Casa de consignação de compra, venda e aluguel de escravos (de Souza, 2010).

A contratação através dos anúncios de jornais, como já mencionado, era uma prática muito comum e popularizada entre a população carioca. A partir deles, destacam-se diversos aspectos da sociedade, como a localização geográfica em que as/os criadas/os europeias/us estavam fixados ao se lançarem no serviço doméstico. Desta maneira, foi traçado um mapa de parte da cidade do Rio de Janeiro, que abarca parte das Zonas Central, Sul e Norte para marcar a porcentagem referente à demanda (precisa-se) e oferta (alugase e oferece-se) criadas/os europeus/eias, em que o endereço do ofertado ou demandado está exposto. Todavia, para que as mudanças fossem perceptíveis ao longo do tempo, no que se refere à localização geográfica, foram elaborados mapas representando dois períodos históricos: 1882-1907 e 1912-1932. 
MAPA 2 - LOCALIZAÇÃO DE CRIADAS/OS EUROPEIAS/EUS EM ANÚNCIOS DE “PRECISA-SE” $(1882-1907)^{10}$

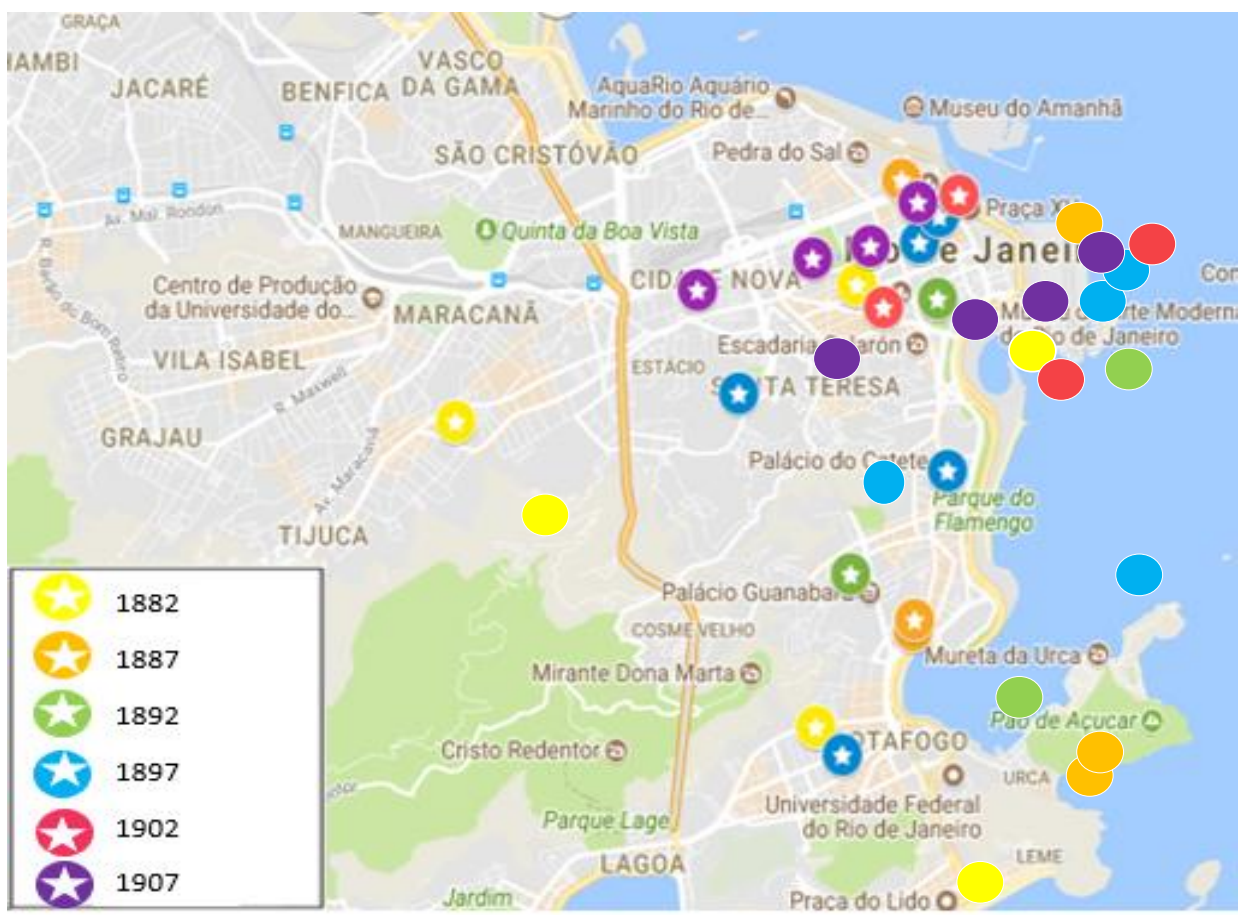

Fonte: Google Maps, localizando geograficamente as ruas (atualizadas quando preciso) citadas em anúncios de precisa-se de criados/as europeus/ias, no período de 1882-1907.

${ }^{10} \mathrm{O}$ número de localizações nem sempre correspondem com o número de anúncios de estrangeiros catalogados em tabelas anteriores, pois havia casos em que a/o criada/o solicitava que as pessoas interessadas entrassem em contato com o escritório do periódico, em que o anúncio foi veiculado. 
MAPA 3 - LOCALIZAÇÃO DE CRIADAS/OS EUROPEIAS/EUS EM ANÚNCIOS DE “PRECISA-SE” $(1912-1932)^{11}$

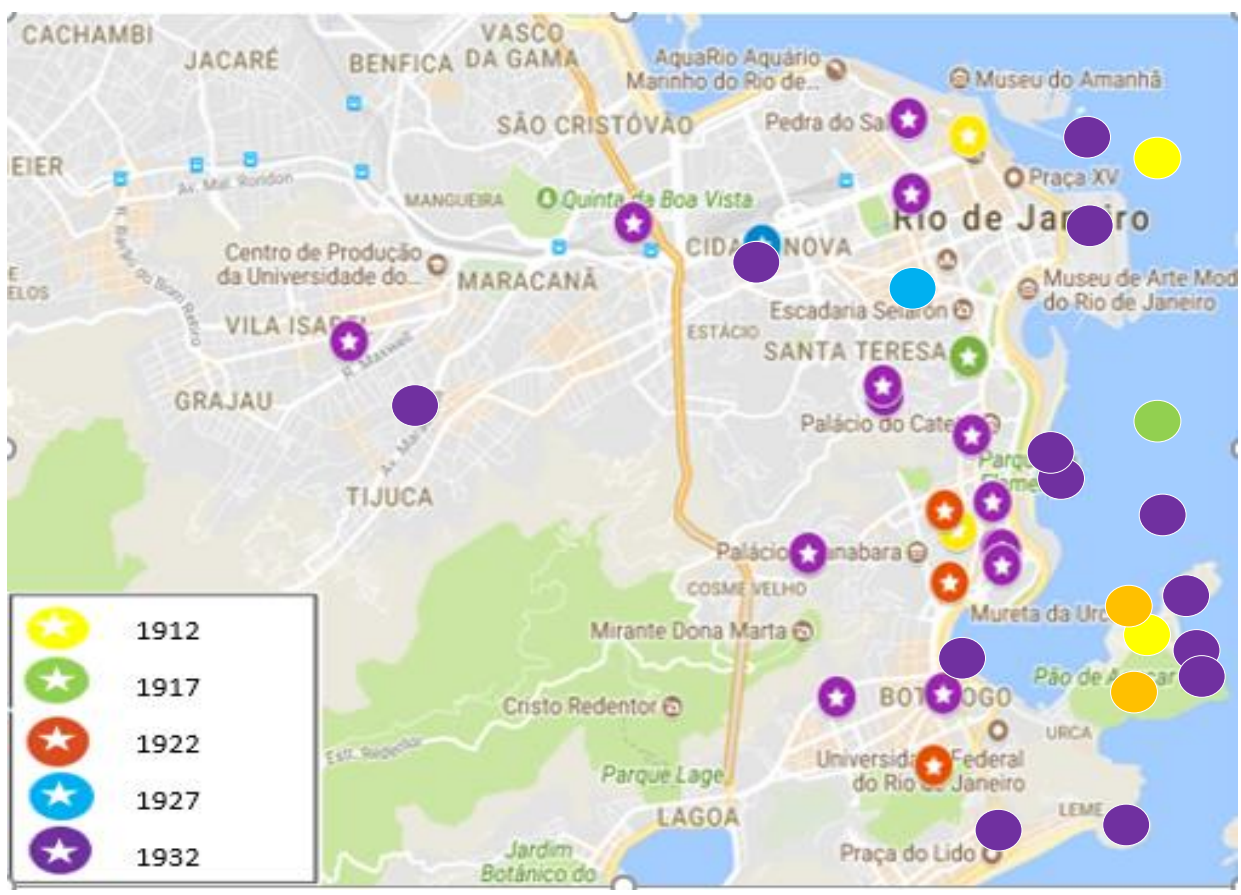

Fonte: Google Maps, localizando geograficamente as ruas (atualizadas quando preciso) citadas em anúncios de precisa-se de criados/as europeus/ias, no período de 1912-1932.

${ }^{11} \mathrm{O}$ número de localizações nem sempre correspondem com o número de anúncios de estrangeiros catalogados em tabelas anteriores, pois havia casos em que a/o criada/o solicitava que as pessoas interessadas entrassem em contato com o escritório do periódico, em que o anúncio foi veiculado. 
MAPA 4 - LOCALIZAÇÃO DE CRIADAS/OS EUROPEIAS/EUS EM ANÚNCIOS DE “ALUGA-SE” $(1882-1907)^{12}$

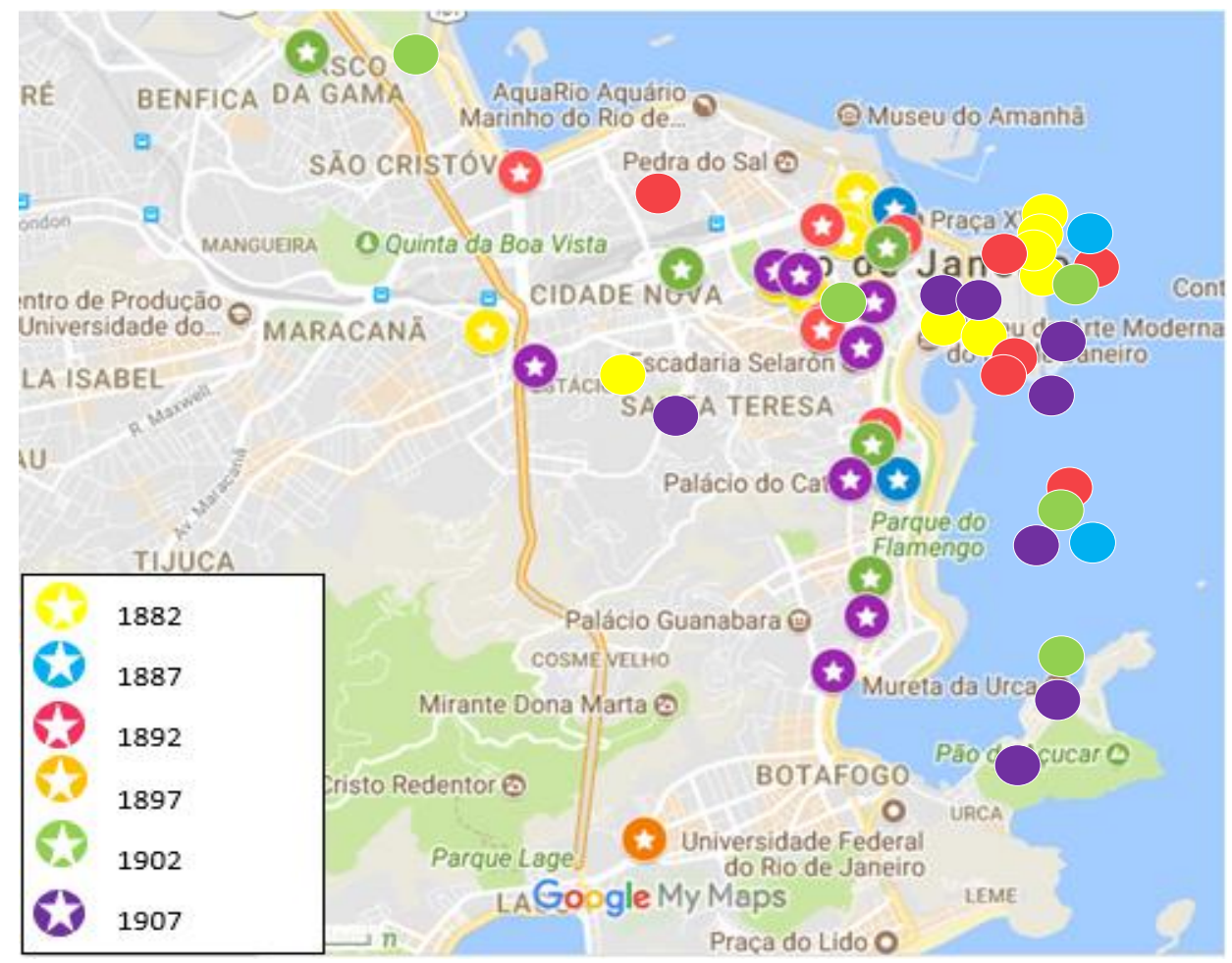

Fonte: Google Maps, localizando geograficamente as ruas (atualizadas quando preciso) citadas em anúncios de precisa-se de criados/as europeus/ias, no período de 1882-1907.

${ }^{12} \mathrm{O}$ número de localizações nem sempre correspondem com o número de anúncios de estrangeiros catalogados em tabelas anteriores, pois havia casos em que a/o criada/o solicitava que as pessoas interessadas entrassem em contato com o escritório do periódico, em que o anúncio foi veiculado. 
MAPA 5 - LOCALIZAÇÃO DE CRIADAS/OS EUROPEIAS/EUS EM ANÚNCIOS DE “ALUGA-SE” $(1912-1932)^{13}$

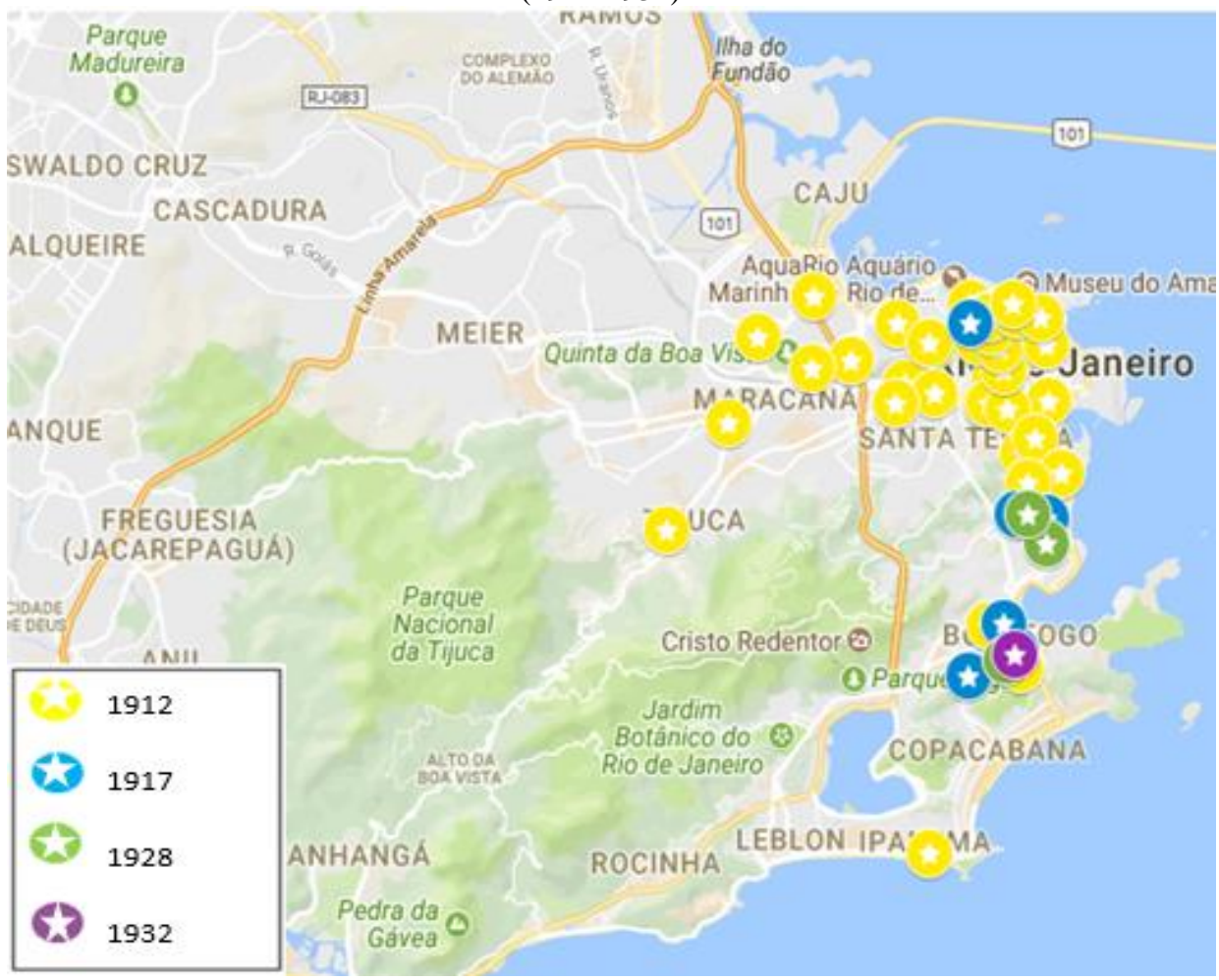

Fonte: Google Maps, localizando geograficamente as ruas (atualizadas quando preciso) citadas em anúncios de precisa-se de criados/as europeus/ias, no período de 1912-1932.

Nos mapas acima, observamos uma concentração maior de imigrantes europeias/eus na região central e sul do Rio de Janeiro. No mapa 2, que se refere ao período de 1882 a 1907, observa-se uma concentração de demanda por criadas/os europeias/eus na Zona Central do Rio de Janeiro. Dos 19 endereços de patrões demandando criadas/os estrangeiras/os, 11 referiam-se a residentes do centro da cidade. Entretanto, no mapa 3, onde se observa a demanda por criadas/os no período de 1912 e 1932, consta-se uma concentração maior de demanda se afastando da região central e partindo para regiões mais afastadas, como Vila Isabel e, sobretudo, a Zona Sul. Esta característica representa uma tendência que

\footnotetext{
${ }^{13} \mathrm{O}$ número de localizações nem sempre correspondem com o número de anúncios de estrangeiros catalogados em tabelas anteriores, pois havia casos em que a/o criada/o solicitava que as pessoas interessadas entrassem em contato com o escritório do periódico, em que o anúncio foi veiculado.
} 
vinha-se desenhando no final do século XIX. ${ }^{14}$ Desde o segundo reinado, foram intensificadas as obras de melhorias e criação de vias de transportes, além do loteamento das antigas chácaras e fazendas da Zona Sul, convertendo-se em novos bairros residenciais de "elite", como Copacabana. Este processo se intensificou a partir de 1890. Entretanto, não se pode desconsiderar o fato de que tais regiões não foram áreas exclusivas de uma elite aristocrática carioca. A Zona Sul foi ocupada, também, por uma população "não aristocrática", principalmente por imigrantes portugueses ligados ao comércio, que trataram de ocupar terrenos menos valorizados nas intermediações do cemitério de São João Batista (Benchimol, 1992, pp. 102-103). De acordo com Jaime Benchimol,

[à] medida que floresciam os bairros residenciais da "elite", desenvolvia-se um mercado local de trabalho relacionado ao comércio (tanto formal como ambulante), à prestação de serviços domésticos, ao exercício de certas profissões e pequenos ofícios, à exploração das pedreiras e outros ramos ligados à construção. (Benchimol, 1992, p. 103)

Se observarmos os mapas referentes aos anúncios em que criadas/os eram ofertadas ou se colocavam ao aluguel (mapas 4 e 5), verificamos uma significativa parcela destes anúncios partindo da Zona Sul, publicados no Jornal do Commercio:

Aluga-se uma moça portuguesa para ama seca; na rua S. Clemente n. 341, Botafogo. ("Aluga-se uma moça portuguesa para ama seca", 1912).

Aluga-se uma moça portuguesa para arrumadeira em prática de pensão e casa de tratamento; dá referências de sua conduta: na praia do Flamengo n. 10 ("Aluga-se uma moça portuguesa para arrumadeira", 1912)

GOVERNANTE - Uma moça alemã, de boa educação, chegada há pouco, oferece-se para casa de família para ensinar meninas, sabendo alemão, inglês, português e piano, não faz questão de ordenado, mas exige bom tratamento; carta a E. 13, no Allens Hotel, rua Humaitá. ("Governante - Uma moça alemã, de boa educação", 1897)

Como tal região se converteu também em uma área com grande concentração de europeus, sobretudo portugueses, a presença de mulheres imigrantes nesta região, bem como de agências de locação, poderia explicar a oferta dessas criadas partindo desta localidade. Além disso, a mobilidade geográfica, da Zona Central para a Zona Sul, ao longo dos anos, por parte dos criados, pode ter acompanhado um movimento realizado pelos patrões. Nos anúncios selecionados das famílias estrangeiras que demandavam por criados, percebe-se uma tendência do deslocamento para a Zona Sul do Rio de Janeiro.

\footnotetext{
${ }^{14} \mathrm{Na}$ verdade, a ocupação de regiões periféricas à Zona Central do Rio de Janeiro, por uma elite, se iniciou logo após a chegada da família real. Regiões como Glória, Catete, Botafogo, Rio Comprido, Engenho Velho e São Cristóvão se transformaram em locais preferenciais para uma classe dirigente estabelecer residência ao longo do século XIX. Em consequência, as classes menos abastadas passaram a ocupar localidades, como bairros da Saúde, Santo Cristo e Gambôa e, ao avançar dos anos, em regiões como a Cidade Nova (o Mangal e São Diogo) (Miceli, 2011).
} 
Precisa-se de uma perfeita lavadeira e engomadeira, podendo dormir fóra; na praia de Botafogo n. 88 ("Precisa-se de uma perfeita lavadeira e engomadeira", 1882)

Precisa-se de um pequeno de 10 a 12 anos, para serviços leves e ajudara copa, tendo casa, comida, bom tratamento e pequeno ordenado, na rua das Laranjeiras n. 11(ileg) ("Precisase de um pequeno de 10 a 12 anos", 1902)

Apesar desse direcionamento geográfico rumo à Zona Sul ter se mostrado uma tendência, a área central ainda era uma região com grande concentração de criadas/os estrangeiras/os se ofertando ao serviço doméstico carioca. Se observarmos os dados censitários referentes à presença de estrangeiros em freguesias do Rio de Janeiro, verifica-se uma significativa presença dessas pessoas, frente a freguesias não englobadas à região central, como por exemplo, a Lagoa, com 1.637, em 1890 e 3.461, em 1906.

TABela 5. ESTRANGEIRAS DO SEXO FEMININO EM FREGUESIAS DAS ZONAS CENTRAL E SUL DO RIO DE JANEIRO

\begin{tabular}{|l|r|r|}
\hline Freguesias & 1890 & 1906 \\
\hline Candelária & 351 & 294 \\
\hline São José & 4.622 & 4.421 \\
\hline Santa Rita & 4.354 & 5.299 \\
\hline Sacramento & 2.554 & 2.831 \\
\hline Glória & 4.106 & 4.744 \\
\hline Sant'Anna & 5.296 & 4.147 \\
\hline São Antônio & 2.289 & 5.161 \\
\hline Espírito Santo & 2.382 & 4.358 \\
\hline Engenho Velho & 2720 & 2266 \\
\hline Lagoa & 1.637 & 3.461 \\
\hline São Cristóvão & 850 & 2.456 \\
\hline Gávea & 273 & 1.142 \\
\hline Engenho Novo & 1493 & 1229 \\
\hline
\end{tabular}

Nota: No recenseamento de 1920, não há a quantidade de imigrantes por freguesias, apenas por municípios.

Fonte: Rio de Janeiro, Oficina de Estatística, 1907.

Ribeiro destaca que, no Primeiro Reinado, a região central do Rio era uma área bastante ocupada pelos lusitanos.

Na freguesia da Candelária ficava parte da rua da Vala e essa região abrigava a maior percentagem de filhos de Portugal (...) Quanto a Santa Rita, onde localizavam a Prainha e o Valongo, se é verdade que homiziava negros e era o local preferido dos 
líberos, era fronteiriça com o mar, fácil de desembarque nas suas muitas ilhotas, de onde os portugueses em situação de ilegalidade podiam alcançar a terra ou escapar em pequenos botes para o interior da baía de Guanabara. (Ribeiro, 1987, p. 84)

Em relação à população hispânica, ela aglomerava-se nos distritos de Santa Rita, Sacramento, São José, Santo Antônio, Espírito Santo, Glória e Gamboa. Eram áreas densamente povoadas, que não passaram pelas reformulações implementadas pelas obras de remodelação organizadas pelo Prefeito Pereira Passos, iniciadas em 1902. Estas regiões eram ocupadas por habitações coletivas (a maior incidência da cidade), o que nos permite deduzir que "recém-chegados compartilhavam com os segmentos mais baixos da população carioca do mesmo padrão de moradia" (Guimarães, 1997, p. 188) ${ }^{15}$. E, certamente, compartilhavam com a população nacional, todas as dificuldades enfrentadas no mundo do trabalho, onde o serviço doméstico poderia se converter em uma atividade de inserção desses imigrantes à sociedade e ao mercado de trabalho carioca.

Essas pessoas, por mais que não vislumbrassem uma carreira mais duradoura no serviço doméstico, exerciam-na como um meio de não caírem na penúria, e, também, de se livrarem das desconfianças e perseguições policiais ao comprovarem serem trabalhadoras lícitas. Mas, é importante deixar destacar que a precarização das relações de trabalho, no final do século XIX e início do século XX, impunha condições de trabalho compulsório e relações arbitrárias, não só à população negra livre e liberta, mas também a alguns imigrantes que poderiam iniciar o processo de precarização e tolhimento de sua total liberdade através dos contratos firmados com as agências de locação, como algumas que pudemos observar através dos anúncios de jornais analisados. De acordo com Luiz Felipe de Alencastro, há uma sobreposição do tráfico de escravos e o tráfico de engajados, a partir de meados do século XIX. Os traficantes e fazendeiros ligados ao comércio atlântico, após a proibição do tráfico legal, em 1831, passaram a utilizar a frota negreira para transportar os engajados de Portugal para o Rio de Janeiro, sobretudo os açorianos (de Souza, 2010). ${ }^{16}$

Em uma escritura de locação de serviços assinada entre Caetano Vargas e sua mulher Claudina Peres, ele espanhol e ela portuguesa, com o Dr. Antônio

\footnotetext{
${ }^{15}$ Érica Sarmiento da Silva informa que, nas ruas e bairros próximos à rua da Ajuda, foram ao longo do século XX, residência de muitos galegos. Regiões como a Rua São José, a Rua dos Arcos, Lavradio, Riachuelo, etc., que compunham as freguesias de São José e Santo Antônio, se transformam em uma verdadeira "mancha" da imigração. Para maiores informações sobre a população galega no Rio de Janeiro, ver de Silva, 2009.

${ }^{16}$ Sobre as casas de aluguel ver Soares, 2007. Sobre o comércio de engajados portugueses ver Alencastro, 1988.
} 
Coelho Rodrigues, fica evidente o papel dessas agências. No contrato analisado, percebe-se que os locadores "obrigam-se a prestar ao locatário durante três anos (...) todos os serviços domésticos internos e externos" e que o locatário:

(...) obriga-se a pagar aos locadores a mensalidade de trinta e dois mil réis em moeda corrente do Brasil dos quais poderá deduzir todos os meses a metade por conta da quantia de duzentos e setenta e seis mil réis que nesta data paga por eles aos senhores Agostinho Pires Companhia. ${ }^{17}$

No contrato estabelecido, fica evidente o papel das agências na locação dos criados, bem como o estabelecimento de dívidas em que os imigrantes ficavam à mercê dos contratos de trabalhos que firmavam o pagamento da dívida aos agenciadores, criando um vínculo de dependência entre esses trabalhadores e o seu futuro patrão, pelo menos até que a dívida com a agência fosse paga. Desta forma, apesar do papel de "facilitador" de inserção de trabalhadoras/es imigrantes, nacionais, livres, libertos e escravizados, no mercado de trabalho, essas agências eram envoltas de desconfianças, seja por parte dos trabalhadores que poderiam se envolver em uma dívida que os levaria a trabalhos compulsórios para o pagamento dela, mas também, sobretudo, pelos patrões.

Portanto, analisar a circulação dessas/es empregadas/os estrangeiras/os por áreas mais abastadas da cidade, não quer dizer que necessariamente, as relações de trabalho estabelecidas seriam melhores do que as de um/a criado/a de cor da região central. A linha que separava o trabalho escravo do livre, mesmo após a abolição da escravidão, ainda era muito tênue. Ser trabalhador/a no Rio de Janeiro, no final do século XIX e início do XX, mesmo sendo europeu, não era uma tarefa fácil. Violências, tolhimento de sua liberdade, baixos ou nenhum salário, eram situações que estes/as trabalhadores/as estavam vulneráveis por não buscar "fazer a América".

\section{CONSIDERAÇÕES FINAIS}

A presente pesquisa, teve como objetivo, realizar um breve panorama das ocupações e circulações de imigrantes europeias no cenário dos mundos do trabalho carioca. Imigrantes essas, que adensavam a Capital Federal, sobretudo a partir dos anos de 1880, quando vimos iniciar a chamada "grande migração", que foi responsável pela entrada considerada de imigrantes europeus no Brasil.

Neste sentido, verifica-se a importância de se pensar sobre a participação das mulheres europeias no serviço doméstico carioca, que apesar de ser

17 Notação: AN. ONRJ.7 - 5I, livro 29, folha 17, rolo 010.007-77 (10/10/1882) - AN 
composto majoritariamente, por mulheres negras, não deixava de ser um espaço para a inserção dessa onda de imigrantes pobres que avolumavam a Capital Federal a partir das últimas décadas Oitocentistas.

Perceber como se dava a circulação dessas pessoas, nos permite acompanhar um processo de elitização das regiões mais afastadas da área central da cidade configurando a Zona Sul como um ambiente de predomínio da elite branca, em contraposição a área central que se caracteriza pela massa de trabalhadoras/es pobres, sobretudo, de cor. E nos permite também, verificar que a elitização da Zona Sul, onde muitos criados estrangeiros se fixaram, não representava, necessariamente, melhores condições de trabalho. As relações laborais, no final do século XIX e início do século XX, não estabeleciam um corte entre trabalho livre e compulsório. Muitas vezes, a força da escravidão precarizava a experiência de liberdade de negros livres e dos demais trabalhadores, incluindo os/as estrangeiros/as. (Chalhoub, 2012, p. 28).

O serviço doméstico, portanto, mostra-se, até hoje, um espaço privilegiado para se observar a precarização das relações laborais e da concepção de trabalho livre assalariado. Para isto, pensar a intersecção entre raça, classe, gênero e etnia se faz necessário para a compreensão das relações de trabalho envolvendo mulheres nacionais negras, mas também algumas europeias, que muitas vezes experienciavam relações de trabalho degradantes e as desconfianças por serem estrangeiras. É evidente que o peso racial operava desigualdades na determinação das relações de trabalho. Ser uma mulher negra, pobre e empregada doméstica evidentemente era mais penoso do que ser uma criada europeia na mesma condição laboral. Entretanto, não podemos desconsiderar as amarguras de ser uma criada estrangeira tentando fazer a vida, mesmo em regiões mais abastadas como a Zona Sul carioca, que apesar da opulência, poderia encobrir duras condições de vida e trabalho.

\section{REFERÊNCIAS}

Alencastro, L. F. (1988). Proletários e escravos: imigrantes portugueses e cativos africanos no Rio de Janeiro, 1850-1872. Novos Estudos Cebrap, (21), 30-56.

Aluga-se uma moça portuguesa para ama seca. (1912, 4 de novembro). Jornal do Comercio.

Aluga-se uma moça portuguesa para arrumadeira. (1912, 4 de novembro). Jornal do Comercio.

Andall, J. (2017). Gender, Migration and Domestic Service: The politics of Black women in Italy. Routledge. https://doi.org/10.4324/9781315254586 
Benchimol, J. L. (1992). Pereira Passos: Um Haussmann Tropical. A renovação urbana da cidade do Rio de Janeiro no início do século XX. Secretaria Municipal de Cultura, Turismo e Esportes, Departamento Geral de Documentação e Informação Cultural, Divisão de Editoração.

Chalhoub, S. (2001). Trabalho, lar e botequim: O cotidiano dos trabalhadores no Rio de Janeiro $d a$ belle époque (2a ed.). UNICAMP.

Chalhoub, S. (2012). A força da escravidão: Ilegalidade e costume no Brasil oitocentista. Companhia das Letras.

Cole, J. E., \& Booth, S. S. (2007). Dirty work: Immigrants in domestic service, agriculture, and prostitution in Sicily. Lexington Books.

Criada estrangeira - precisa-se de uma. (1910, 13 de maio). Jornal do Comercio.

da Costa Leite, J. (2000). O Brasil e a emigração portuguesa (1855-1914). In B. Fausto (ed.), Fazer a América: A imigração em massa para a América Latina (2a ed., pp. 177-200). Universidade de São Paulo.

Damasceno, C. (2011). Segredos da boa aparência: da "cor" à "boa aparência" no mundo do trabalho carioca (193-1950). Edur; UFRRJ.

de Medeiros, L. M., \& de Matos, M. I. S. (2017). Gênero e imigração: Mulheres portuguesas em foco (Rio de Janeiro e São Paulo - XIX e XX). e-Manuscrito.

de Silva, É. S. (2009). Um passeio pelas ruas do Rio Antigo: pioneiros galegos, a Rua da Ajuda e o mercado ambulante. Revista o Arquivo Geral da Cidade do Rio de Janeiro, (3), 95-108.

de Souza, F. F. (2010) Para casa de família e mais serviço: O trabalho doméstico na cidade do Rio de Janeiro no final do século XIX [Dissertação de mestrado, Universidade do Estado do Rio de Janeiro].

Distrito Federal. (1907). Planta da cidade do Rio de Janeiro do guia profissional adoptado na força policial do Districto [mapa]. http://objdigital.bn.br/objdigital2/acervo_digital/div_cartografia/cart1407012/cart1407012.jpg

Edmundo, L. (2003). O Rio de Janeiro do meu tempo. Conselho Editorial do Senado Federal.

Fausto, B. (ed.). (2000). Fazer a América: A imigração em massa para a América Latina (2a ed.). Universidade de São Paulo.

Fortes, A., Espada Lima, H., Lima Xavier, R. C., \& Ferraz Petersen, S. R. (2013). Cruzando Fronteiras: Novos olhares sobre a história do trabalho. Fundação Perseu Abramo.

Galeano, D. A. (2012). Criminosos viajantes, vigilantes modernos: Circulações policiais entre Rio de Janeiro e Buenos Aires, 1890-1930 [Tese de doutorado, Universidade Federal de Rio de Janeiro].

Graham, S. L. (1992). Proteção e obediência: Criadas e seus patrões no Rio de Janeiro, 1860-1910 (V. Bosi, trad.). Companhia das Letras.

Graham, S. L. (2005). Caetana diz não: Histórias de mulheres da sociedade escravista brasileira (P. M. Soares, trad.). Companhia das Letras.

Governante - Uma moça alemã, de boa educação. (1897, 1 de novembro). Jornal do Comercio, 8.

Guimarães, L. M. P. (1997). Breves Reflexões sobre o problema da imigração urbana: O caso dos espanhóis no Rio de Janeiro (1880-1914). Acervo, 10(2), 179-198. 
IBGE (2017). PNAD Contínua 2017: Realização de afazeres domésticos e cuidados de pessoas cresce entre os homens, mas mulheres dedicam quase o dobro do tempo. http://agenciadenoticias.ibge.gov.br/agencia-sala-de-imprensa/2013-agencia-de-noticias/releases/20911pnad-continua-2017-realizacao-de-afazeres-domesticos-e-cuidados-de-pessoas-cresce-entre-os-homens-mas-mulheres-ainda-dedicam-quase-o-dobro-do-tempo.html

Klein, H. S. (2000). Migração internacional na História das Américas. In. B. Fausto (ed.), Fazer a América: A imigração em massa para a América Latina (2a ed., pp. 13-31). Universidade de São Paulo.

Lima, H. E. (2005). Sobre o domínio da precariedade: Escravidão e os significados da liberdade de trabalho no século XIX. Topoi, 6(11), 289-326. https://doi.org/10.1590/2237$101 X 006011004$

Miceli, B. S. (2011, 10-14 de maio). O desenvolvimento do espaço urbano do Rio de Janeiro: Principais observações a partir do Paço da Cidade. Anais do I Simpósio Brasileiro de Cartografia Histórica, Paraty. https://www.ufmg.br/rededemuseus/crch/simposio/MICELI_BRUNA_S.pdf

Momsen, J. H. (1999). Gender, migration, and domestic service. Routledge.

Precisa-se de um pequeno de 10 a 12 anos. (1902, 13 de maio). Jornal do Comercio.

Precisa-se de uma arrumadeira. (1910, 13 de maio). Jornal do Comercio.

Precisa-se de uma boa e carinhosa ama de leite. (1920, 13 de maio). Jornal do Comercio, 16.

Precisa-se de uma copeira e arrumadeira. (1915, 13 de maio). Jornal do Comercio.

Precisa-se de uma criada para cozinhar e mais serviços. (1915, 13 de maio). Jornal do Comercio.

Precisa-se de uma perfeita lavadeira e engomadeira. (1882, 6 de novembro). Jornal do Comercio.

Ramos, J. de S. (1996). Dos males que vêm com o sangue: as representações raciais e a categoria do imigrante indesejável nas concepções sobre imigração na década de 1920. In M. C. Maio (ed.), Raça, ciência e sociedade (pp. 59-82). FIOCRUZ; CCBB.

Ribeiro, G. S. (1987). "Cabras" e "Pés-de-chumbo": Os rolos do tempo. O antilusitanismo na cidade do Rio de Janeiro (1890-1930) [Dissertação de mestrado, Universidade Federal Fluminense].

Rio de Janeiro, Oficina de Estatistica. (1907). Recenseamento do Rio de Janeiro (Districto Federal). https://biblioteca.ibge.gov.br/visualizacao/livros/liv49678.pdf

Soares, L. C. (2007). O "Povo de Cam" na capital do Brasil: A escravidão urbana no Rio de Janeiro. Faperj; 7 Letras.

Trento, A. (1989). Do outro lado do Atlântico: Um século de imigração italiana no Brasil. Nobel.

van der Linden, M. (2013). Trabalhadores do mundo: Ensaios para uma história global do trabalho (P. de Queiroz Carvalho Zimbres, trad.). Unicamp. 